\title{
Berglund, Bruce R. and Brian Porter-Szücs, eds. 2013. Christianity and Modernity in Eastern Europe. Budapest and New York: Central European University Press. 386 pp.
}

\section{Reviewed by Dorottya Nagy, University of South Africa, Helsinki, Finland}

Christianity and Modernity in Eastern Europe is a collection of thirteen essays about the results of a collaborative project that lasted from 2005 to 2010 and involved over twenty historians from Europe and North America who sought to "address methodological approaches and interpretative problems in the larger fields of church history and religious studies" (XV). The volume proposes two major goals, one of which is to show the significance of Christianity in Eastern Europe to unfamiliar readers who are searching for the meaning of Christianity and/or religion in the twentieth and twenty-first centuries. The way these goals are formulated suggests that from the perspective of history studies, these essays focus on the interrelatedness of what is defined as Eastern Europe (geography), Christianity (religion) and modernity (historical period), and emphasize the relevance of this interrelatedness within a broad context of inquiries. The contributors also aim to show how in reality the relationship of time, place and religion was and is far more complex than what is suggested by currently pervasive stereotypes.

In the abovementioned framework, the contributions of editors Bruce R. Berglund and Brian Porter-Szücs act as an instrumental infrastructure that provides the reader with necessary insights into the project as well as some of the results presented in the essays of the other historian contributors. In his introductory chapter, Porter-Szücs refers to Hans Georg Gadamer's (1900-2002) term of hermeneutic circles to describe the contributors of the volume as mediators and translators who "are moving from explanation to a search for meaning and understanding $[\ldots]$ to narrow the gap between alien worldviews and to appreciate as fully as possible the motives and the goals of historical agents (without $[\ldots]$ surrendering one's own critical perspectives)" (9-10). In order to achieve this goal, the contributors not only have to pay careful attention to individual subjectivity and agency, but also critically reconsider those theories and terminologies that previously failed to reflect the everyday experiences and actions of believers. These considerations entail a critical approach to existing historiographies and their foci of interest by keeping in mind that Christianity is more than publicly confessed doctrines, officially accepted theologies and institutional embodiments.

One of the ways in which the contributing historians of the volume bring human agency into a focal point is by making a clear distinction between Christianity defined as "a set of broad frameworks for perceiving and understanding the world" and Christians viewed as "the people who lived within those frameworks" (3), with both definitions kept intentionally vague in order to capture the fluidity of human agents and their relationship to the world. Both categories are defined so loosely that they could essentially be replaced by any other identifier such as Judaism, Islam, "worldview," "culture" or even "modernity." The book does acknowledge the nondescript nature of these definitions and soon clarifies that Christianity is discussed in this volume as a

(cc) $\mathrm{Br}$

ULLS D-Serle
New articles in this journal are licensed under a Creative Commons Attribution 4.0 International License.

This journal is published by the University Library System of the University of Pittsburgh as part of its D-Scribe Digital Publishing Program and is cosponsored by the University of Pittsburgh Press 
Nagy, Dorottya. "Berglund, Bruce R. and Brian Porter-Szücs, eds. 2013. Christianity and Modernity in Eastern Europe." Hungarian Cultural Studies. e-Journal of the American Hungarian Educators Association, Volume 7 (2014): http://ahea.pitt.edu DOI: 10.5195/ahea.2014.155

broader category encompassing many subcategories such as Catholics, Protestants and Orthodox Christians, and where Protestants are broken down further into Lutherans and Calvinists, the Catholics into Ukrainian Greek Catholics, and the Orthodox believers are categorized according to their respective nation states. These additional categories are just as vague as the original categories of Christianity or Christians, which may be the reason why in his attempt to provide a working definition for Christianity, Porter-Szücs came to the conclusion that "Christianity is delineated yet fluid, constraining yet enabling and always under construction" (13). However, the purpose of such a broad definition is to empathize how Christianity and any of its conceptual counterparts can be meaningfully addressed, discussed and reflected upon from the perspective of human agents and their approach to and understanding of the world through their respective beliefs.

After reading the essays, one may conclude that these abstractions of Christianity are simply tools for addressing questions about identity. For instance, Natalia Shlikhta's essay on the Ukrainian Greek Catholic Church or Galia Valtchinova's inquiries into what it means to be Orthodox Christian in Bulgarian society are but two poles that address the fluidity of human identities as studied through the abstraction of Christianity, while both Paul Hanebrink's research on interwar Christian Hungary and James Felak's case study of individuals in Slovakia aim to show that identities should be conceived as reflexive processes instead of as static worldviews (see also Michal Pagis, "Religious Self-Constitution: A Relational Perspective," in Courtney Bender et al. eds., Religion on the Edge; Oxford: Oxford University Press, 96-97).

The concept of modernity in this volume emerges within the fluid dynamic of human agency described above and is conceived as a rubric denoting "tumultuous transformations" within, mainly, the twentieth century such as "capitalist industrialization and the Great Depression, the rise of the radical right and racial politics, World War II, Stalinism, the actually existing socialism from the 1960s to the 1980s, and the apparent triumph of neoliberalism since the 1990s" (17). Within this broad framework that emphasizes the fluidity and diversity of human agents and the worldviews they produce, the volume suggests that those who study modernity and its relationship with Christianity should be able to interpret the acts of the will made under various socio-political settings of the various nation-states. The following essays of the volume translate these concerns into a fascinating array of topics based on will and person, two crucial concepts "when questions of action and agency" are concerned according to Thomas Pfau's Minding the Modern: Human Agency, Intellectual Traditions, and Responsible Knowledge (Notre Dame: University of Notre Dame Press, 2013, 14). For instance, human rights (Katharina Kunter), education (Hanebrink), peace (David Doellinger), belief and socio-political order (Patrick Hyder Patterson), religious diversity (James Bjork and Andreas Kossert), as well as the person and his/her situatedness (Anca Şincan) within culture (Martin C. Putna) are but a few topics through which the diverse history of "modernity" is presented to the reader.

The way the conceptual framework of the project translates into essays also reveals the methodological struggle of combining the abstractions of Christianity and "modernity," especially when we consider that the noun "modernity" and its derivative adjective "modern" can be used to denote a worldview, an understanding of the world as well as one's identity and place in the social order. The fact that most of the essays do not or hardly use the terms "modernity" or "modern" further underlines the necessity of addressing the theoretical questions entailed in examining the relationship of Christians, Christianity and modernity. In this regard, the discussion initiated by some of the contributors to the volume could certainly benefit from dwelling more substantially into on theological understandings of modernity and touching on 
Nagy, Dorottya. "Berglund, Bruce R. and Brian Porter-Szücs, eds. 2013. Christianity and Modernity in Eastern Europe." Hungarian Cultural Studies. e-Journal of the American Hungarian Educators Association, Volume 7 (2014): http://ahea.pitt.edu DOI: 10.5195/ahea.2014.155

other aspects of everyday life such as family, sexuality, gender, leadership and entrepreneurship. "Modernity," then, is largely presented in the volume as an un-problematized and invariably masculine construct, with a few exceptions such as Valtchinova's article on the "remaking" of religion in Socialist Bulgaria, in which the author offers a deconstruction of the traditionally accepted religious field in Bulgaria through the case of Vanga (Evangelia) Pandeva Gushterova (1911-1996). Vanga was a blind and poor Orthodox woman who attracted a massive following on account of her visions, premonitions and spiritual experiences and soon caught the attention of political leaders as well, who viewed her as challenging politics to address the issue of religion in Bulgaria. Valtchinova illustrates how in their eagerness to settle the issue of faith and modernity in Bulgaria, different political ideologies as well as the Orthodox Church continuously assessed Vanga in ways that strengthened their own arguments.

The third key term of the volume is Eastern Europe, which at first glance seems to suggest area studies but which comes to be used across the essays in ways that do not clarify to the reader whether the volume's choice of terminology hides an epistemological assumption of the legitimacy of an east-west paradigm or not. The transparency of the term is greatly reduced by the way several contributors seemingly use the terms "Central and Eastern Europe" and "East Central Europe" to refer to the same area, and how the concept of "Eastern Europe" is also broken down into certain nation states for the purposes of individual contributors, but the fact that the case of the German Democratic Republic strongly features in the selection (Kunter and Doellinger) seems to confirm the presence of an east-west axis. Nevertheless, whenever the construct of "Eastern Europe" becomes a focal point in research, this happens through the identification and geographical demarcation of regions where "the social, economic, and political processes that have characterized the continent's modernity were experienced belatedly, if at all" and where "communist regimes held power from the 1940s to the 1989s" (16). Berglund builds on Walter Brueggemann's theological conceptualization of place to argue that "Eastern Europe" is also a "conceptual place, with no visible boundaries or objective features, yet it remains fixed in most people's geographic imaginations" and in this sense, "it can influence religious belief and practice" (330). Berglund's argument also implies that the juxtaposition of the elements mentioned in the title of the volume could be perceived as a triangulation of the concepts of Christianity, modernity and Eastern Europe.

Hanebrink partly explores the dynamics of the above mentioned triangulation in an article titled "Christianity, Nation, State: The Case of Christian Hungary," in which he contemplates the complexities of Christianity and the Hungarian socio-political order by examining the interwar period rhetoric of Hungary being or once again becoming a purely Christian nation. Hanebrink eases his readers into the subject through a detailed description of the interwar period in Hungary, during which both politicians and church leaders engaged in politics called for a moral revival and the revitalization of Christianity and Christian values in Hungarian society as the only path towards a brighter future for the Hungarian nation. Hanebrink then proceeds to deconstruct the apparently unified program for realizing a Christian Hungary by highlighting the conflicts, negotiations and compromises among Christians from every tier of society and regardless of their economic, political or religious affiliation as they faced the pressing question of what was the right relationship between religion and state in the age of modernity. As a result, the reader is presented with a wide spectrum of options between nationalism and missionization, where the consensus between Hungarian Christians invariably seems to have emerged with regard to the subject of the "Jewish question." Hanebrink argues that the line of Anti-Semitic rhetoric calling for a united Christian nation stems from the 1880 's, a time when the concept of a 
Nagy, Dorottya. "Berglund, Bruce R. and Brian Porter-Szücs, eds. 2013. Christianity and Modernity in Eastern Europe." Hungarian Cultural Studies. e-Journal of the American Hungarian Educators Association, Volume 7 (2014): http://ahea.pitt.edu DOI: 10.5195/ahea.2014.155

Christian Hungary was envisioned "against the predations of "Jewish power" (64) and can be traced up to "the moment of crisis" in 1944 (81). This article also supports Berglund's argument about Eastern Europe as a place (versus "space") with historical meanings where certain things are remembered in certain ways and through remembrance, and where different identities remain and manage to relate in spite of all their contradictions.

One of the volume's strong points, as demonstrated above, is that it offers fresh takes on old questions, but looking at the relationship of the editors' programmatic framework and its implementation by the contributions might cause a sense of dissatisfaction in readers as the frame seems to be larger than the actual picture portrayed. While I do not dispute the legitimacy of focusing on Catholics, Protestants and Orthodox Christians and investigating their participation in the history of the twentieth and twenty-first centuries in Eastern Europe, it would have been useful to include other Christians in a discussion of modernity as it was exactly within this historical period that the issue of diversity in the Eastern European region was further complicated by the emergence of Christian Others (see Catherine Wanner, Communities of the Converted: Ukrainians and Global Evangelism; New York: Cornell University Press, 2007). In this regard, concepts such as Berglund's "spiritual geography" become even more problematic since Berglund's own construct of religiosity is largely based on Catholic or Orthodox terminology (e.g. sacred sites, holy lands, sacramental places), and as such may prove inapplicable to other tenets of Christianity that would be worth investigating. The reader is also left wondering why the historians contributing to the volume neglected the primary sources of other religions such as Judaism or Islam in addressing the question of how non-Christians assessed the role of Christians and Christianity in shaping the history of Eastern Europe. Some of these questions could have been addressed either through a more detailed description of the process of essay selection for the volume, or by a narrower framework that stretches no further than the actual picture emerging within it.

Although the reflective reader might be able to see the triangulation of Christianity, modernity and Eastern Europe throughout the essays, the purpose of the volume might have been better served by establishing a connection between the presented case studies and the rest of the world at large. Offering levels of comparison and extending the east-west dichotomy (Kossert) would have certainly been beneficial to readers who are not familiar with the Eastern European region but have an extended knowledge about other parts of the world. Placing the issue of Christianity and modernity in Eastern Europe within an extended global framework would have also allowed readers to engage more easily in dialogue with the volume, especially when it invites us to perceive Eastern Europe as "a relational story, a drama of differences perceived and real, of associations and rejections" (353). Nevertheless, even if these shortcomings might leave some readers frustrated, one should keep in mind Berglund's words of hope that the "volume will open up new lines of research" into what he calls "East European Christianity" (332).

As a volume of selected essays addressing the interrelatedness of geography, religion and a historical period, Christianity and Modernity in Eastern Europe will appeal to a large spectrum of readers. It calls for historians to explore new ways of writing/composing historiographies on Christianity and modernity, challenges theologians to enter into a dialogue with non-theological research on Christianity and modernity, and invites students of Hungarian Cultural Studies to investigate the ways in which the contributing historians tackle these basic concepts. All these directions and possibilities would make the volume an exciting addition to academic courses centered on the juxtaposition of Christianity and modernity. 